\title{
Estado e Sociedade: Conflitos e Relações de Poder
}

\author{
Altemar Felberg \\ Danielle Ferreira Medeiro da Silva de Araújo \\ Eva Dayane Almeida de Góes ${ }^{3}$
}

Resumo: Esse ensaio trata dos conflitos e das relações de poder entre Estado e Sociedade, sob a perspectiva do embate entre o que é normativo, institucionalizado e legitimado na/pela figura do Estado, em contraposição ao conjunto de práticas socialmente construídas e utilizadas pela sociedade civil como mecanismo e estratégia de enfrentamento e de luta social. Nesse sentido, esse texto traz três abordagens que pretendem dialogar sobre essa problemática, trazendo, primeiro, a construção das normas legais e sociais e como estas se interacionam; segundo, tratando as violências institucional e simbólica como formas de violação direta aos direitos humanos e liberdades fundamentais, que precisam ser fortemente combatidas, individual e coletivamente e;terceiro e por último, refletindo o direito de resistência como mecanismo de luta por direitos fundamentais e de enfrentamento à heteronomia estatal. A proposta é argumentar de que maneira a sociedade pode e deve se sublevar contra o Estado em situações em que este exerce o poder de forma arbitrária, opressora e violenta.

Palavras-chave: Estado. Normas. Sociedade. Violência.

\begin{abstract}
This essay deals with the conflicts and power relations between State and Society, under the perspective of the clash between what is normative, institutionalized and legitimized in/by the figure of the State, as opposed to the set of practices socially constructed and used by civil society as a mechanism and strategy for confrontation and social struggle. In this sense, this text has three approaches that intend to dialogue about this problem, bringing, first, the construction of legal and social norms and how these are interacted; Secondly, treating institutional and symbolic violence as forms of direct violation of human rights and fundamental freedoms, which need to be strongly opposed, individually and collectively; Third, and finally, reflecting the right of resistance as a mechanism for fighting for fundamental rights and facing state heteronomy. The proposal is to argue how society can and should revolt against the state in situations in which it exercises power in an arbitrary, oppressive and violent manner.
\end{abstract}

Keywords:State. Standards. Society. Violence.

\section{Introdução}

É na luta de forças entre sociedade e Estado que os homens constroem e desconstroem as relações sociais. A sociedade, imbuída de normas próprias, por meio dos hábitos e costumes, vai

\footnotetext{
${ }_{1}^{1}$ Mestrando do Programa de Pós-Graduação em Estado e Sociedade, do Centro de Formação em Ciências Humanas e Sociais da Universidade Federal do Sul da Bahia (UFSB). Membro do Grupo de Pesquisa Paidéia. Bolsista da Fundação de Amparo à Pesquisa da Bahia (FAPESB). E-mail: felberg_imt@hotmail.com.

${ }^{2}$ Mestranda do Programa de Pós-Graduação em Estado e Sociedade, do Centro de Formação em Ciências Humanas e Sociais da Universidade Federal do Sul da Bahia (UFSB). Membro do Grupo de Pesquisa Paidéia. Bolsista da Fundação de Amparo à Pesquisa da Bahia (FAPESB). E-mail: dannymedeiro@hotmail.com.

3 Mestranda do Programa de Pós-Graduação em Estado e Sociedade, do Centro de Formação em Ciências Humanas e Sociais da Universidade Federal do Sul da Bahia (UFSB).E-mail: evadayane.ufsb@gmail.com.
}

Página 171 Caderno de Ciências Sociais Aplicadas, Vitória da Conquista/BA, vol. 14, n² 24, ano 14, p. 171-190, jul/dez 2017. 
ressignificando o social. Compreender a gênese das normas que fundamentam a força do Estado e da sociedade é também encontrar caminhos para a melhor análise dos fenômenos sociais de nosso tempo.

Os autores jusnaturalistas falam em um Estado de natureza em que os homens vivem segundo uma lei natural. Assim, é a partir dessa que a vida social é delineada e construída, até o momento em que os homens decidem constituir o Estado por meio de um contrato social. Para Jonh Locke (1994, p. 83) no estado de natureza "Os homens são absolutamente livres para decidir suas ações, dispor de seus bens, e de suas pessoas como bem entenderem". É um tempo marcado pela paz, boa-vontade, assistência mútua e preservação, que pode se transformar em estado de guerra, caso haja o uso da força ou a intenção declarada de força de um sobre o outro, sem que haja alguém para julgar. É para fugir desse conflito e buscar um poder de decisão que o consentimento acontece por parte de todos para a formação de uma sociedade civil com o fim de proteção dos direitos que já existiam em um estado de natureza.

Outro pensador contratualista, Jean Jacques Rousseau (1762), acreditava que os homens eram livres e iguais no estado de natureza. O homem como um ser bom e independente se une aos outros para se preservar e conservar. Sendo assim, "o pacto social, em vez de destruir a igualdade natural, concede-lhe, pelo contrário, uma igualdade moral e legítima onde a natureza tinha criado uma desigualdade física, e os homens que na força e no gênio são desiguais, torna-se iguais pela convenção e pelo direito" (ROUSSEAU, 2010, p.35).

Já para Hobbes (1651), o direito de natureza, a que os autores geralmente chamam jus naturale, é a liberdade que cada homem possui de usar seu próprio poder, da maneira que quiser, para a preservação de sua própria natureza, ou seja, de sua vida; e consequentemente de fazer tudo aquilo que seu próprio julgamento e razão lhe indiquem como meios adequados a esse fim. De acordo com o autor, os homens são iguais por natureza, mas a discórdia entre estes, que pode ser causada pela competição, desconfiança e glória, levam a um estado de "guerra de todos contra todos", e na busca pela paz, os homens acordariam um contrato social.

O fundamento jusnaturalista de acordo social para a formação do Estado não marca o fim de conflitos advindos da pluralidade social; pelo contrário, guardaria em si mesmo um direito natural de resistência aos arbítrios do próprio Estado. E para explicar essa relação conflituosa, Clastres (1974) entende o Estado como instrumento que permite à classe dominante exercer sua dominação violenta sobre as classes dominadas, revelando, na verdade, a história social da luta da sociedade contra o Estado.

Página 172 Caderno de Ciências Sociais Aplicadas, Vitória da Conquista/BA, vol. 14, n 24, ano 14, p. 171-190, jul/dez 2017. 
Dessa forma, é a partir desse caminho queo artigo pretende, por um lado, expor o uso da força do Estado manifestado através do Direito, entendido como instrumento simbólico de unificação social, e os desvios da prerrogativa da força configurada em uma violência institucional. Por outro, observar o poder da sociedade fortalecido em normas sociais e no direito de resistência civil, que põe em cheque o objetivo da coesão social. A metodologia deste trabalho baseia-se em uma pesquisa bibliográfica realizada a partir dos registros disponíveis em fontes impressas e digitais.

\section{A construção das normas legais e sociais para a compreensão de um conflito}

\section{A construção das normas legais no campo do Direito Público}

No Direito Público, os juristas definem tradicionalmente o Estado a partir de três elementos constitutivos: o povo, o território e a soberania. Segundo Mortati (1969, p. 23), o Estado é "um ordenamento jurídico destinado a exercer o poder soberano sobre um dado território, ao qual estão necessariamente subordinados os sujeitos a eles pertencentes". Neste sentido, para Gaglietti (2006, p. 45), o Estado organiza o monopólio legítimo da violência, logrando uma obediência civil que se submete aos valores sociais prescritos na lei. Assim, como explica Warat (1995, p.59-60) "a razão de Estado fica identificada com a racionalidade do saber jurídico e da lei positiva como uma forma de impor-nos interesses e desejos legalizados, quer dizer, que estes passam a ser os mesmos desejos e interesses que outorgam consistência simbólica ao Estado.” Segundo Gaglietti (Ibid.),

O direito é a forma por excelência do poder simbólico, uma vez que o discurso jurídico, dadas as condições históricos sociais necessárias, é capaz de criar as coisas que nomeia. Essa dimensão simbólica adquirida pelo direito, ao simular linguisticamente sua própria unidade, constrói sua esfera ilusória da igualdade de todos perante a lei. Trata-se assim de uma violência simbólica por ser erigida em uma sociedade sem conflitos - ao menos na aparência e na crença de tal aparência - sem vontades, sem diferenças culturais e sem tempo histórico.

Para Gaglietti (2006, p.46) observa-se que "a retórica jurídica constrói um sujeito universal, imparcial e objetivo, que está acima da experiência da vida. Além disso, empenha-se em mostrar a existência de um consenso ético, ocultando a pluralidade social". E é no campo desta pluralidade social que a sociedade constrói normas e regras próprias, que ora se submetem ao rigor da lei, ora são contrárias aos ditames legais, sendo, assim, considerada uma ilegalidade. De acordo com o mesmo

Página 173 Caderno de Ciências Sociais Aplicadas, Vitória da Conquista/BA, vol. 14, nº 24, ano 14, p. 171-190, jul/dez 2017. 
autor (p. 45) "o conflito, dentro dessa ordem, é sempre encarado como o desvio de uma normalidade, ou seja, como uma transgressão do regramento jurídico".

Nesse sentido, as normas legais operam como instrumento da força simbólica do Estado para legitimar a visão legítima do mundo. Segundo Bourdieu (2009, p.9), este poder de enunciação do mundo só seria possível quando ignorado como arbitrário, sendo ele capaz da construção da realidade para o estabelecimento de uma ordem, chamado de poder simbólico. Diante do conflito entre normas legais e normas sociais, observa-se que apesar do formalismo legal, existem outras normas informais que vigoram com força de lei dentro da sociedade. Segundo Gaglietti (2006, p.46), "assim, atribui-se a ordem legal uma obrigatoriedade, quando, na verdade, as normas jurídicas estão sujeitas às oscilações provocadas pelos resultados nas disputas no campo social”. No campo social encontramos diferentes normas que expõem recursos comunitários valiosos - como festejos, produção cultural, saberes rurais, por exemplo, mas também é onde observamos a prevalência de normas sociais fundamentadas na desigualdade social que permanecem difíceis de serem superadas em nossa história, como o trabalho infantil, a violência doméstica, o aliciamento de crianças e adolescentes pelo tráfico de drogas, entre outros.

Assim, no Brasil fala-se em uma dualidade jurídica, ou seja, uma lei formal e outras leis informais. De acordo com Gaglietti (2006, p. 48)

Constata-se a existência de uma separação entre a lei formal e os usos e costumes praticados cotidianamente pela maioria da população, ou seja, as leis no Brasil receberam e recebem um tratamento da ordem do formal (o estabelecido na Constituição, por exemplo) e da ordem do informal (o estabelecido nas normas e regras construídos no dia-a-dia). No Brasil é comum as comunidades criarem regras e normas informais, estabelecidas pelas experiências grupais e aceitas pela maioria da população porque nelas se reconhece muito mais do que nas leis formais. Essa legislação informal revela, de certo modo, a obediência a códigos implícitos, porque não legalizados oficialmente.

Para interpretar tal paradoxo brasileiro, Souza (1999) formula duas hipóteses: a primeira diz respeito à existência de traduções nacionais do contrato social liberal moderno, particularmente, do princípio da igualdade; a segunda refere-se à existência de formas específicas de vivências das leis, com a produção e utilização de mecanismos diferenciados, como por exemplo, a elaboração de códigos informais, que deslocam para outro espaço e práticas, a articulação da lei. Segundo o aludido autor (1999, p.78):

Página 174 Caderno de Ciências Sociais Aplicadas, Vitória da Conquista/BA, vol. 14, n 24, ano 14, p. 171-190, jul/dez 2017. 
[...] teríamos no país o estabelecimento de um contrato social, não no molde liberal, orientador das sociedades modernas, mas sim contratos sociais e podemos entendêlos assim porque tem força de lei, estabelecidos entre duas ou mais pessoas que respeitam essas normas. Assim, as regras particulares, erigidas por estes contratantes, podem generalizar-se, assumindo o caráter de leis, passando a orientar e produzir subjetividades que nelas se reconheçam, explicando à "moda nacional" do contrato social, a capacidade e, mesmo, a necessidade do país de assujeitamento.

Diante dessa pluralidade do campo social, segundo Bourdieu (2009, p.246-247), a norma jurídica quando consagra um conjunto de regras sociais com caráter universalizante, para além das diferenças de condição e de estilo de vida, as mesmas possuiriam um efeito de normalização de uma cultura legítima que considera todas as práticas diferentes como desviantes, anômicas, e até mesmo anormais, patológicas. Assim, aobservância dos diferentes modos de vida que se estabelecem no campo social é parte integrante da relação dialética entre fato, valor e norma que perfaz o fenômeno jurídico. A compreensão das normas sociais possibilita a atualização das normas jurídicas quanto aos valores, interesses e necessidades sociais, além de se configurar também como reveladora de desigualdades sociais a serem superadas na sociedade.

\section{A construção das normas sociais: o problema da superação de normas violadoras de direitos}

Em meio a diversas normas e regras sociais construídas de maneira informal dentro da sociedade, pode-se observar, também, a persistência de normas sociais fundamentadas na desigualdade social que ainda não foram erradicados no Brasil. A partir da cronologia legislativa internacional e nacional,nota-se uma caminhada garantidora de direitos humanos, fundamentados na dignidade da pessoa humana; entretanto, percebe-se, também, que as leis não bastam para a superação de problemas sociais existentes, sendo necessária a sua efetivação no campo social.

Para a superação do hiato existente entre a lei e sua efetividade, se faz necessária a combinação da eficácia jurídica, sinalizando aos agentes públicos sua aptidão para incidir com a eficácia social, sinal de que os agentes destinatários estão dispostos a cumprir e a fazer cumprir suas determinações. Nesse sentido, Barroso (2001, p.13) leciona, in verbis:

Cabe distinguir da eficácia jurídica o que muitos autores denominam de eficácia social da norma, que se refere, como assinala Reale, ao cumprimento efetivo do Direito por parte de uma sociedade, ao "reconhecimento" (Anerkennung) do Direito pela comunidade ou, mais particularizadamente, aos efeitos que uma regra suscita através de seu cumprimento.

Página 175 Caderno de Ciências Sociais Aplicadas, Vitória da Conquista/BA, vol. 14, n² 24, ano 14, p. 171-190, jul/dez 2017. 
O reconhecimento das normas legais pela comunidade traduz a eficácia social de uma norma jurídica e sua real efetividade na vida em sociedade. O estudo das normas sociais possibilita uma maior aproximação dos distintos processos de sociabilização que acontecem na sociedade, evidenciando a existência de leis informais, para além do tecnicismo das normas legais. A definição de normas sociais seria descrito por Bichieri (2013, p. 1) como

[...] um padrão de comportamento tal que as pessoas têm uma preferência para seguir esse padrão quando acreditam que muitas das pessoas de sua rede de referência comportam-se desse jeito, muitas pessoas da sua rede de referência acham que pessoas como elas deveriam comportar-se desse jeito.

Assim, nosso comportamento dependeria do que achamos que os outros fazem e aprovam ou reprovam. Para a referida autora, a norma social é baseada em preferências condicionais e dois tipos de expectativas: empírica e normativa. As expectativas empíricas seriam a crença de que um suficiente número de pessoas em semelhante situação obedecerá à norma (ou o fizeram no passado). Por expectativas normativas seria a crença de que um número suficiente deoutras pessoas acha que devemos obedecer à norma nessa situação, e pode até estar dispostos a nos punir de forma positiva ou negativa, dependendo da nossa escolha de obedecer ou infringir a norma.

O que se observa, em espaços sociais marcados pela desigualdade de acesso ao capital, é que tais normas coletivas, que possuem força e influenciam comportamentos dentro de um grupo social, podem estar fundamentadas em diferentes formas de violência, que passam a ser naturalizadas em pensamentos e formas de agir. Para uma análise holística destes fenômenos, uma proposta de aproximação das normas legais e sociais no campo das políticas públicas através de diferentes mecanismos de participação social seria estratégica como espaço participativo e democrático de trocas, saberes e diversidade. Um encontro necessário, tanto para valoração e reconhecimento dos recursos comunitários, quanto para se delinear soluções conjuntas para os desafios coletivos.

\section{A violência institucional e a violação de direitos humanos}

Antes da constituição dos Estados nacionais centralizadores e monopolizadores dos recursos de força, a violência era entendida como uma forma indispensável à garantia da vida dos homens, os quais tinham suas experiências cotidianas guiadas pela expectativa da guerra, já que se fazia necessário serem socializados mediante valores que dessem sustentação ao estado permanente de guerra. (SOARES apud DIAS, 2010, p. 24).

Página 176 Caderno de Ciências Sociais Aplicadas, Vitória da Conquista/BA, vol. 14, n 24, ano 14, p. 171-190, jul/dez 2017. 
Assim, ao pensarmos em violência, estamos determinados a pensar sempre na violência física. Entretanto, para além do uso da força física, o Estado pratica uma diversidade de outras violências. Nesse sentido, abordaremos neste capítulo a agressão que ocorre todos os dias nos órgãos públicos de forma silenciosa e naturalizada, que pode ser imperceptível, e em muitos casos nem assimiladas enquanto violência, pois está baseada em regras e normas institucionalizadas há muito tempo.

A Constituição Federal de 1988, em seu artigo 5º traz o princípio da isonomia, que diz que “todos somos iguais perante a lei”, uma máxima do regime democrático que indica um tratamento justo e igual a todo cidadão brasileiro. Essa igualdade deveria ser o alicerce basilar para uma convivência pacífica e homogênea na nossa sociedade; contudo, é uma igualdade que não se propaga a todos e diariamente estamos mais predispostos a perceber as falhas que atingem o sistema social.

O Estado continua a fazer uso de práticas autoritárias e discriminatórias em nome da ordem e da lei. Essas práticas afetam principalmente os grupos mais vulneráveis socialmente (crianças e adolescentes, mulheres, negros, índios, pobres etc.), que assim permanecem excluídos, marginalizados e diariamente violentados ao não ter condições de acessar seus direitos. Weber (2008) diz que em nossos dias, a relação entre o Estado e a violência é particularmente íntima.

De acordo com o Conselho Nacional de Justiça (CNJ), a

violência institucional é um tipo de violência motivada por desigualdades (de gênero, étnico-raciais, econômicas, etc.) predominantes em diferentes sociedades. Essas desigualdades se formalizam e institucionalizam nas diferentes organizações privadas e aparelhos estatais, como também nos diferentes grupos que constituem essas sociedades (CNJ, 2017).

Para o Ministério da Saúde, a violência institucional

é aquela exercida nos/pelos próprios serviços públicos, por ação ou omissão. Pode incluir desde a dimensão mais ampla da falta de acesso à má qualidade dos serviços. Abrange abusos cometidos em virtude das relações de poder desiguais entre usuários e profissionais dentro das instituições, até por uma noção mais restrita de dano físico intencional (MINISTÉRIO DA SAÚDE, 2002, p.21).

A violência institucional revela-se essencialmente por fatores como a atuação desqualificada e incompetente dos profissionais, pelos problemas e má gestão dos programas e recursos das instituições, pela falta de informações dadas aos usuários, pela organização e dificuldades de acesso dos cidadãos aos sistemas educativos, sociais, de saúde, justiça etc., (VIEIRA, 2013) ou mesmo pela ineficácia ou falta de providências que forçam o cidadão a fazer uma verdadeira peregrinação pelos serviços sem que consiga

Página 177 Caderno de Ciências Sociais Aplicadas, Vitória da Conquista/BA, vol. 14, nº 24, ano 14, p. 171-190, jul/dez 2017. 
resolver suas demandas. Ela acontece diariamente dentro das instituições, principalmente através das regras e normas políticas e burocráticas, refletindo estruturas sociais injustas. (MINAYO apud ARAÚJO et al., 2011).

Ao desqualificar saberes práticos em razão dos saberes científicos; ao ignorar, destratar ou maltratar usuários por conta de sua orientação sexual, gênero, cor, classe social, idade ou deficiência; ao proibir acompanhantes ou restringir demais os horários de visitas; ao tratar com frieza, rispidez, negligência ou omissão, ao não ter tempo suficiente para um atendimento adequado; e ao negar acesso a medicamentos e outros serviços, estamos diante de práticas corriqueiras, muitas delas instituídas como regras e normas a serem seguidas para o "bom funcionamento" da instituição. Todavia, são práticas que agridem diretamente o ser humano e sua dignidade.

Saffioti (2015) afirma que quando a modalidade de violência mantém limites tênues com a chamada normalidade, devemos usar o conceito de 'direitos humanos'. Assim, o campo da violência institucional relaciona-se diretamente com o debate dos Direitos Humanos. É um tema com uma difusão ainda muito incipiente na sociedade, mas uma prática muito comum em órgãos públicos que deveriam proteger e defender os direitos dos cidadãos. A violência institucional contribui diretamente para a manutenção de uma ordem social injusta e para a conservação do status quo da classe dominante.

À luz das lições de Martinez, ao relacionarmos a violência institucional com os Direitos Humanos, estamos dizendo que esse tipo de agressão, ipsis litteris:

é incompatível com a construção de uma sociedade, que respeite plenamente à Dignidade da Pessoa Humana. Os Direitos Humanos têm como valor-fonte a Dignidade da Pessoa Humana e é fator determinante para a aplicação da Constituição Brasileira. O Estado existe para garantir e promover a Dignidade de todas as pessoas [...] (MARTINEZ, 2008, p.3).

A declaração Universal dos Direitos Humanos em seu artigo $1^{\circ}$ diz que "todos os seres humanos nascem livres e iguais em dignidade e em direitos. Dotados de razão e de consciência, devem agir uns para com os outros em espírito de fraternidade" (DUDH, 1948).

Para Martinez (2008), a fraternidade é o princípio que rege as ações humanas no sentido de que devemos ser solidários em relação aos outros seres humanos. Nessa perspectiva, a violência praticada por agentes públicos é a completa negação da fraternidade e a violação bruta dos direitos e da dignidade da pessoa humana.

Página 178 Caderno de Ciências Sociais Aplicadas, Vitória da Conquista/BA, vol. 14, n 24, ano 14, p. 171-190, jul/dez 2017. 
Este é o tipo de violência que muitas vezes não agride fisicamente, que não faz o disparo e que não fere a olho nu, mas que violenta a partir do desgaste físico e emocional, da descrença nos seus direitos e da impossibilidade de acessar a cidadania, causando impactos imensuráveis na vida dos indivíduos e gerando um caos social, muito perceptível principalmente nas grandes cidades.

"Se existissem apenas estruturas sociais das quais a violência estivesse ausente, o conceito de Estado teria também desaparecido e apenas subsistiria o que, no sentido próprio da palavra, se denomina 'anarquia"' (WEBER, 2008, p.60). Para Weber (2008) a violência não é o único instrumento que o Estado possui, mas é seu instrumento específico, de forma exclusiva e fundamentada em lei.

Em seu livro 'A Sociedade Contra o Estado' Pierre Clastres narra todos os processos realizados pelas sociedades primitivas em não permitir o surgimento do Estado. Acredita-se que, intrinsecamente, as sociedades primitivas percebiam que sua liberdade e sua organização social estariam ameaçadas pelo poder e pela força que o Estado viria a impor.

O Estado, dizem, é o instrumento que permite à classe dominante exercer sua dominação violenta sobre as classes dominadas. Que seja. Para que haja o aparecimento do Estado, é necessário, pois, que exista antes divisão da sociedade em classes sociais antagônicas, ligadas entre si por relação de exploração (CLASTRES, 1978, p. 14).

A violência institucional, perpetrada diariamente pelo Estado, é contemplada na abordagem de Souza (2015, p. 5) sobre a violência simbólica, que diz que

a reprodução de todos os privilégios injustos no tempo depende do "convencimento", e não da "violência". Melhor dizendo, essa reprodução depende de uma "violência simbólica", perpetrada com o consentimento mudo dos excluídos dos privilégios, e não da "violência física".

Um conceito fundamental, quando tratamos de violência simbólica, é o conceito de poder simbólico elaborado pelo sociólogo francês Pierre Bourdieu. Há, segundo o sociólogo, um poder que se deixa ver menos ou que é até mesmo invisível. Esse poder, que é exercido pela ausência de importância dada a sua existência, poder ignorado,fundamenta e movimenta uma série de outros poderes e atos. (COSTA, 2015).

Para Bourdieu, "O poder simbólico é, com efeito, esse poder invisível o qual só pode ser exercido com a cumplicidade daqueles que não querem saber que lhe estão sujeitos ou mesmo que o exercem" (BOURDIEU, 1989, p. 7). De tal modo, as classes privilegiadas vão mantendo sua

Página 179 Caderno de Ciências Sociais Aplicadas, Vitória da Conquista/BA, vol. 14, nº 24, ano 14, p. 171-190, jul/dez 2017. 
dominação através das instituições públicas (e privadas) que controlam, cometendo a violência simbólica e institucional de maneira silenciosa por meio de relações assimétricas e hegemônicas, da desqualificação dos usuários dos serviços públicos e da manutenção de preconceitos e violências de todos os tipos.

Esse poder simbólico usufruído pelas elites é um "poder quase mágico, que permite obter o equivalente daquilo que é obtido pela força (física ou econômica), graças ao efeito específico de mobilização, só se exerce se for reconhecido, quer dizer, ignorado como arbitrário". (BOURDIEU, 1989, p. 14).

Em Souza (2015, p. 33) podemos observar como a discriminação do Estado se transforma em violência quando ele diz que "[...] o Estado e seus agentes passam a agir como age o homem cordial na vida cotidiana: dando tudo aos amigos e reservando aos inimigos a letra dura da lei".

Embora a situação tenha adquirido níveis assombrosos de violação dos direitos humanos, a sociedade civil tem se mobilizado na direção da realização de denúncia e na publicização nas redes sociais dos episódios mais chocantes.

A violência institucional é, sem sombra de dúvidas, uma violação dos direitos humanos e a negação da cidadania. Dessa forma, é preciso pensar em políticas capazes de modificar efetivamente o quadro caótico que vivenciamos nas instituições brasileiras, para combatê-la e reduzi-la, minimizando suas consequências cruéis, visando evitar e impedir sua manutenção e propagação, eliminando-a do cotidiano dos agentes públicos, garantindo assim, que os cidadãos possam ter seus direitos assegurados e respeitados ao buscar instituições públicas cujo dever é servir a sociedade.

\section{Direito de resistência como mecanismo de luta por direitos fundamentais e enfrentamento à heteronomia estatal}

A atual conjuntura do Estado brasileiro, reconhecidamente, nos apresenta, de forma bastante clara, um cenário de grande instabilidade - política, econômica e social. Tempos marcadamente conflituosos, em que se opõem, de um lado, militantes de um projeto político democratizante e universalizante da cidadania, onde se evidencia a ampliação dos espaços para que o cidadão participe dos processos de discussão e decisão políticas; e de outro, defensores de um Estado mínimo, liberalista, com cada vez menos responsabilidade estatal com a garantia dos direitos civis e respeito às liberdades fundamentais (DAGNINO, 2005).

Página 180 Caderno de Ciências Sociais Aplicadas, Vitória da Conquista/BA, vol. 14, n 24, ano 14, p. 171-190, jul/dez 2017. 
Nesse contexto de acirrada disputa - típico das democracias modernas - intensificam-se os conflitos entre Estado e sociedade civil, seguindo o movimento de luta por direitos que teve início na década de 1970 contra o regime militar, em que, posteriormente, os movimentos "Diretas Já" (1984), “Fora Collor" (1992), "Passe Livre” (2013) e, de forma permanente, "Luta pela Reforma Agrária” (pós 1964), se caracterizam como alguns dos mais expressivos e capazes de traduzir esse cenário de polarização extrema da sociedade, atualmente podendo ser chamado de "guerra civil fria", fazendo uma analogia à fórmula de guerra fria desenvolvida por Raymond Aron (1951), cujo pressuposto é "paz impossível, guerra improvável”.

Analisando esses três primeiros ciclos de protestos que envolveram a democracia no Brasil, especificadamente, Tatagiba (2014) conclui que a radicalização, a polarização e o uso da violência como estratégias de luta contra o Estado, vieram para ficar, ainda que isso não se traduza na instituição de uma guerra civil pura, mas, certamente, em manifestações populares cada vez mais intensas, violentas e radicais na reivindicação e luta por direitos.

É justamente sob essa perspectiva, da importância do direito de resistência como instrumento de luta pela efetivação de direitos, que este capítulo pretende tratar; com a proposta de contribuir com as mais recentes e problematizadoras reflexões sobre os conceitos de "poder" e "direito" no âmbito das discussões sobre construção democrática; especialmente, o direito de resistência civil como mecanismo de enfrentamento direto às heteronomias do Estado, respaldado no princípio da soberania popular e no que a Constituição da República Federativa do Brasil (1988) prevê em seu art. 1º, $\int$ único, que diz que: "Todo o poder emana do povo, que o exerce por meio de representantes eleitos ou diretamente (...)", reforçado, também, pelo que estabelece a Declaração dos Direitos do Homem e do Cidadão (1793) em seu Art. 35 “Quando o governo viola os direitos do povo, a insurreição é, para o povo e para cada parcela do povo, o mais sagrado dos direitos e o mais indispensável dos deveres”.

Preliminarmente à apresentação do contexto histórico em que surgiu e se desenvolveu o direito de resistência, sua origem e evolução ao longo dos tempos, faz-se necessário sua definição. De acordo com Diniz (2005, p. 181/2), o direito de resistência é aquele:

Página 181 Caderno de Ciências Sociais Aplicadas, Vitória da Conquista/BA, vol. 14, n 24, ano 14, p. 171-190, jul/dez 2017. 
Direito reconhecido aos cidadãos, em certas condições, de recusa à obediência e de oposição às normas injustas, à opressão e à revolução. Tal direito concretiza-se pela repulsa a preceitos constitucionais discordantes da noção popular de justiça; à violação do governante da ideia de direito de que procede o poder cujas prerrogativas exerce; e pela vontade de estabelecer uma nova ordem jurídica, ante a falta de eco da ordem vigente na consciência jurídica dos membros da coletividade. A resistência é legítima desde que a ordem que o poder pretende impor seja falsa, divorciada do conceito ou ideia de direito imperante na comunidade. $O$ direito de resistência não é um ataque à autoridade, mas sim uma proteção à ordem jurídica que se fundamenta na ideia de um bem a realizar. Se o poder desprezar a ideia do direito, será legítima a resistência, porém é preciso que a opressão seja manifesta, intolerável e irremediável.

Em breve retrovisão histórica, verifica-se que a resistência como direito começou a ganhar seus primeiros contornos no pensamento político da antiguidade, tanto na Grécia Antiga, como no Império Romano. Todavia, antes mesmo dos gregos e romanos, os povos do oriente já previam a rebelião como castigo divino ao governante que decidisse ir contra as leis e mandamentos vigentes, previsto no código Hamurabi, criado por volta do século XVIII a.C. baseado na lei de talião, "olho por olho, dente por dente". Evidentemente que esse direito estava restrito ao direito natural do homem de se opor e resistir a opressões externas, a fim de garantir a ordem pública como o maior bem da sociedade. Assim, não havia qualquer reconhecimento por parte do Estado à resistência como direito, até porque, na época, a figura do Estado como instituição política, não existia como hoje a conhecemos.

Na Grécia Antiga, a resistência como direito surge - salvo a observância a outras situações principalmente por meio da peça "Antígona", escrita por Sófocles, que retratava os símbolos de resistência ao tirano e de obediência à razão - obra que acabou, mais tarde, repercutindo na doutrina clássica da teoria da resistência. Na peça, o autor defendia a supremacia das leis da razão humana, em detrimento dos códigos morais escritos, na hipótese de um embate entre essas, partindo do pressuposto de que as leis injustas do soberano vão contra os princípios do direito natural. Ao retratar a questão da desobediência de Antígona às decisões tirânicas de Creonte, Rei de Tebas, a obra reflete e discute sobre o confronto entre os dois pilares da moralidade política: a justiça divina e a justiça humana.

$\mathrm{Na}$ Idade Média, São Isidoro, Bártolo e São Tomás de Aquino são reconhecidos como os grandes precursores do direito de resistência, especialmente este último (COSTA, 2006). Para o autor, esses desenvolveram relevantes ideias sobre tirania e resistência.

Sob forte influência da Igreja Católica, a doutrina política medieval defendia a ideia de que o direito de resistência deveria ser considerado como um direito natural e um dever moral político, sendo, assim, reconhecido e assegurado o direito do cidadão desobedecer às ordens do monarca, caso estas

Página 182 Caderno de Ciências Sociais Aplicadas, Vitória da Conquista/BA, vol. 14, nº 24, ano 14, p. 171-190, jul/dez 2017. 
infringissem os preceitos católicos. Nesse contexto, a resistência não era contra a autoridade estatal em si, mas contra toda e qualquer ação tirânica do soberano que agisse contra a vontade de Deus. Vale a ressalva, ainda segundo o autor, que o direito natural de resistir não possuía nenhum caráter revolucionário ou reformador da ordem social e estatal constituída - o que surgiu somente a partir do pensamento político liberal. Tinha por finalidade dois princípios básicos: regular as relações entre senhores feudais e seus servos, e assegurar a conduta cristã dos soberanos.

Já na modernidade, por volta do século XVII, o filósofo inglês e idealizador do liberalismo, John Locke (1632-1704), criou, no âmbito de suas teorias contratualistas, um tratado sobre o direito de resistência, sendo um forte defensor de tal direito, assim como de muitos outros direitos fundamentais do indivíduo, baseado no sentimento natural de equidade.

Para Locke, o cidadão é provido de um direito legítimo de sublevação, caso a situação de heteronomia estatal do momento exija, ou seja, tem o direito de se levantar contra a ordem instituída, caso esta se oponha aos anseios e interesses da sociedade. No pensamento de Locke, no instante em que o homem decide, livremente, abrir mão de seu estado de natureza para firmar um contrato social, o direito de resistência de funda e se legitima. Foi então, a partir do pensamento liberal do final do século XVII e início do século XVIII que o direito de resistência foi considerado com um direito fundamental do indivíduo, tratado desta forma na Declaração dos Direitos do Homem e do Cidadão (1793), elaborada pós Revolução Francesa.

Nessa perspectiva de oposição e resistência às situações de abuso de autoridade pelos poderes executivo e legislativo, Maria Garcia (2004), elenca uma série de juristas que, a partir do pensamento liberal, reconheceram a legitimidade da resistência à opressão: Savigny, que defendia que o direito decorre do espírito geral que une a todos, defendendo a revolução fundada no desejo de substituição do governo que se oponha às transformações reclamadas; Bluntschli, que justificava a revolução da mesma maneira; Ihering, que defendia o uso da força para salvar a existência da nação, mesmo com o sacrifício do direito; Benjamin Constant, para quem, se a Constituição é violada, não há governo de direito; Vareilles Sommières, que argumentava que a resistência justifica-se pela ideia de legítima defesa.

Em síntese, podemos considerar que "o direito de resistência defendido por Locke, a teoria da separação dos poderes de Montesquieu e a ideia da lei, expressão da vontade geral do povo, como o único fundamento para a autoridade soberana de Rousseau" cimentaram a base do Estado de Direito surgido final da Idade Moderna, segundo Araújo (2001, p 34).

Página 183 Caderno de Ciências Sociais Aplicadas, Vitória da Conquista/BA, vol. 14, n 24, ano 14, p. 171-190, jul/dez 2017. 
Avançando na história, já no século XIX, registra-se uma perda de interesse ao direito de resistência, na visão de Bobbio (1992). Para o autor, o motivo teria sido ideológico e institucional, pois na passagem do Estado liberal para o democrático, houve um processo de acolhimento e regulamentação de exigências da burguesia, contendo e delimitando o poder tradicional. Isso se deu através da separação dos poderes (Montesquieu) e da criação do Estado de direito. Ademais, em se tratando de uma democracia, falar em direito de resistência parecia não fazer muito sentido, já que num governo "do povo e pelo povo", não se admite processos heterônomos que limitam ou elidem a vontade popular, a exemplo da tirania ou opressão, não cabendo, portanto, ao menos no âmbito legal, processos de resistência.

Dessa forma, com o advento do regime democrático e seus fundamentos, não se encontra o direito de resistência na maioria dos ordenamentos jurídicos da atualidade. Entretanto, duas importantes democracias europeias do século XX têm expressado em suas constituições esse direito: a Lei Fundamental da República da Alemanha, de 1949, e a Constituição Portuguesa, de 1982. Para Maria Garcia (2004), estas duas democracias consagraram o direito de resistência como princípio de suas cartas magnas, permitindo a resistência em caso de ofensa aos direitos humanos e liberdades fundamentais do cidadão.

Notadamente que um dos elementos fundantes e primordiais para a democracia é a prevalência da vontade popular em detrimento do interesse particular; considerando-se que a vontade geral (Rousseau) deve estar acima do interesse estatal ou das elites, ainda mais quando este estiver desfigurado por abusividade do poder. Sob essa ótica, Dallari afiança que:

Quando um governo, ainda que bem intencionado e eficiente, faz com que sua vontade se coloque acima de qualquer outra, não existe democracia. Democracia implica autogoverno, e exige que os próprios governados decidam sobre as diretrizes políticas fundamentais do Estado" (DALLARI, 2009, p. 311).

No Brasil, especificadamente, a Constituição Federal de 1988, é um dos muitos ordenamentos jurídicos que não expressam o direito de resistência. Entretanto, segundo Maria Helena Diniz (1988), este direito encontra-se implícito na $\mathrm{CF}$, em seu art. $5^{\circ}, \mathbb{\Omega} 2^{\circ}$, que diz "ninguém pode ser obrigado a fazer ou deixar de fazer alguma coisa senão em virtude de lei". E "se houver uma revolução, sendo legítima e vitoriosa, seus autores estarão isentos de responsabilidade, porque as normas emanadas do poder revolucionário, baseadas em novos valores, constituirão normas-origens, isto é, fontes originárias

Página 184 Caderno de Ciências Sociais Aplicadas, Vitória da Conquista/BA, vol. 14, n 24, ano 14, p. 171-190, jul/dez 2017. 
do direito, revogando as normas do regime jurídico anterior e conferindo legitimidade ao ato revolucionário".

Na interpretação de Monteiro (2003, p. 195),

Se os direitos fundamentais possuem aplicabilidade imediata $\left(\llbracket 1^{\circ}\right.$ do artigo $5^{\circ}$ da $\mathrm{CF} / 88$ ) e se "ninguém está obrigado a fazer ou deixar de fazer alguma coisa senão em virtude de lei" (artigo $5^{\circ}$, inciso II da CF/88), então o cidadão poderá resistir, por meio de ações práticas que eventualmente podem até se confundir com a autotutela exercida contra o Estado, como forma de coibir o abuso do poder político e garantir a preservação dos seus direitos violados ou ameaçados.

Igualmente, a desobediência civil como forma de resistência exsurge da "cláusula constitucional aberta”, prevista no art. $5^{\circ}, \mathbb{S} 2^{\circ}$, “in verbis": “Os direitos e garantias expressos nesta Constituição não excluem outros decorrentes do regime e dos princípios por ela adotados, ou dos tratados internacionais em que a República Federativa do Brasil seja parte".

É consenso entre os estudiosos no assunto de que há três causas que ensejam ou até justificam o direito à resistência na atualidade. São elas: a tirania, a opressão e a corrupção.

No Brasil, analisando a atual conjuntura política, podemos certamente reconhecer a corrupção como a principal causa justificadora do direito de resistência, uma vez que reforça as desigualdades, coloca em cheque a democracia representativa e viola radicalmente os direitos e liberdades fundamentais asseguradas na Constituição. Para Maria Garcia (2004, p. 173/4) a "corrupção e opressão são formas correspondentes, aliás, que motivam a insatisfação dos governados, seja qual for o conceito que se tenha do Estado...”.

O direito da resistência apresenta as seguintes espécies, segundo Buzanello (2010): a) objeção de consciência; b) greve política; c) desobediência civil; d) direito à revolução; e) princípio da autodeterminação dos povos. Dentre estas, o conceito de desobediência civil é o mais estudado, não havendo, porém, espaço neste trabalho para o seu merecido aprofundamento. No Brasil, não obstante o "pacifismo" do povo brasileiro, a desobediência civil tem ocorrido nos principais ciclos de protestos já trazidos no início deste capítulo: "Diretas Já” (1984), "Fora Collor” (1992), "Passe Livre” (2013), entre outros.

Nesse contexto, o filósofo americano RAWLS (1981, p. 273) define desobediência civil como “(...) ato público, não violento, consciente e, apesar disto, político, contrário à lei, geralmente praticado com o intuito de promover modificação na lei ou práticas do governo”.

Página 185 Caderno de Ciências Sociais Aplicadas, Vitória da Conquista/BA, vol. 14, n 24, ano 14, p. 171-190, jul/dez 2017. 
Um exemplo emblemático na defesa da desobediência civil é de Martin Luther King (19291968) e sua Marcha sobre Washington de 1963, que motivado pela defesa dos direitos civis e políticos dos negros norte-americanos no período pós II Guerra Mundial, utilizou-se dos ideais da desobediência civil, clamando a opinião pública, pregando a não violência e a resistência pacífica.

Segundo Maria Garcia (2004, p. 293), a desobediência civil é

uma forma particular de resistência ou contraposição, ativa ou passiva do cidadão, à lei ou ato de autoridade, quando ofensivos à ordem constitucional ou aos direitos e garantias fundamentais, objetivando a proteção das prerrogativas inerentes à cidadania, pela sua revogação ou anulação.

Maria Helena Diniz (1997, p. 97) também entende que a desobediência civil "é executada com o fim imediato de mostrar publicamente a injustiça, a ilegitimidade e a invalidade da lei e com o fim mediato de induzir o poder a mudá-la".

Assim, analisando este breve panorama da origem e evolução do direito de resistência, seja como direito natural na antiguidade, seja como pressuposto de regulação e transformação social na idade moderna, podemos inferir que o direito de resistir deve ser visto e considerado, especialmente na atualidade, como um direito fundamental e legítimo do indivíduo e, por conseguinte, de uma sociedade, que emerge do conflito entre dois sentimentos humanos: o dever de obediência e o senso de justiça, ambos considerados cruciais para a preservação e continuidade da vida social. A questão é, qual destes sentimentos deve prevalecer? Previsto ou não no ordenamento jurídico brasileiro, uma certeza a nação deve ter: a de que o direito constitucional de uso legítimo da força pelo Estado nunca deve prevalecer ao direito natural e legítimo do povo de se sublevar a toda e qualquer situação de heteronomia e opressão.

\section{Conclusão}

Por fim, o objetivo do trabalho foi o de evidenciar os conflitos que perpassam o Estado e a Sociedade e como o uso da força permeia um campo de batalha no campo social. Se de um lado o Estado se fundamenta no uso exclusivo da força que se manifesta simbolicamente pela lei, por outro, a sociedade recorre a estratégias de mobilização que também concentram poder e delineiam a vida social.

O que se percebe é que o Estado, em meio a uma intensa produção legislativa, não dá conta de controlar todos os fatos sociais que acabam se formatando a partir de normas sociais próprias. Estas

Página 186 Caderno de Ciências Sociais Aplicadas, Vitória da Conquista/BA, vol. 14, n 24, ano 14, p. 171-190, jul/dez 2017. 
revelam o distanciamento da sociedade brasileira pela impessoalidade, mas também podem esconder pensamentos e ações que violam os direitos humanos, e neste caso precisam ser superadas.

Porém, quando o Estado é o principal violador, cabe à sociedade o direito de resistência civil, coletivo ou individual, que instrumentalize não sobre o direito positivo, mas como fundamento natural, a possibilidade de luta contra a exclusão, a discriminação, a injustiça, a corrupção e a violência.

\section{Referências}

ARAÚjO, Cláudia Rezende Machado de. O Direito Fundamental de Resistência na Constituição Federal de 1988. 2001. 145f. (Dissertação de Mestrado em Direito). Universidade Federal de Pernambuco, 2001.

ARAÚJO, Naira et al. Violência Institucional: violências no cotidiano da equipe de enfermagem. 2010. Disponível em: <http://www.scielo.br/pdf/reben/v64n1/v64n1a13.pdf> Acesso em 10 de maio de 2017.

ARON, Raymond. Paz e Guerra Entre as Nações. Brasília: Editora UnB, 2002.

BARROSO, Luís Roberto. O direito constitucional e a efetividade de suas normas - limites e possibilidades da Constituição brasileira. 5. ed. Rio de Janeiro, Renovar, 2001, p. 13.

BICHIERI, Cristina. Norms, conventions and the power of expectations. To appear in Philosophy of Social Science, N.Cartwright and E. Montuschi, eds., Oxford University Press. Fev 2013. Disponível: <https://sites.sas.upenn.edu/behav-ethics/files/pss_oxford_feb.2013.pdf > Acesso em: 23 nov. 2017.

BOAVENTURA, de Sousa Santos. Por uma concepção multicultural de direitos humanos. Revista Crítica de Ciências Sociais. nº 48. Junho. 1997.

BOBBIO, Norberto. A era dos direitos. Rio de Janeiro: Campus, 1992.

BOBBIO, Norberto. Estado, Governo, Sociedade: para uma teoria geral da política. Paz e Terra. $14^{\mathrm{a}}$ edição. 2007. p. 56, 57.

BOURDIEU, Pierre. O poder simbólico. Trad. Fernando Tomaz, $12^{\mathrm{a}}$ ed. Rio de Janeiro: Bertrand Brasil, 2009.

BOURDIEU, Pierre. O poder simbólico. Rio de Janeiro: Bertrand Brasil S.A, 1989. Disponível em <http://lpeqi.quimica.ufg.br/up/426/o/BOURDIEU_Pierre._O_poder_simb\%C3\%B3lico.pdf> Acesso em 27 de maio.

BRASIL. Constituição (1988). “Constituição da República Federativa do Brasil”: promulgada em 5 de outubro de 1988. Organização do texto: Juarez de Oliveira. 4. ed. São Paulo: Saraiva, 1990. (Série Legislação Brasileira).

Página 187 Caderno de Ciências Sociais Aplicadas, Vitória da Conquista/BA, vol. 14, n 24, ano 14, p. 171-190, jul/dez 2017. 
BUZANELLO, José Carlos. Direito de resistência. Disponível em: $<$ http://www.buscalegis.ufsc.br/arquivos/Direito $\% 20 \mathrm{de} \% 20$ resist $\%$ EAncia.pdf $>$. Acesso em: 8 ago. 2010.

CLASTRES, Pierre. A Sociedade Contra o Estado. trad. Theo Santiago. Coletivo Sabotagem, 1974.

CLASTRES, P. A Sociedade Contra o Estado. Rio de Janeiro: Francisco Alves Editora S.A. 1978.

CONSELHO NACIONAL DE JUSTIÇA. Disponível em: <http://www.cnj.jus.br/programas-eacoes/lei-maria-da-penha/formas-de-violencia>. Acesso em 13 de maio de 2017.

COSTA, Neila S. O Poder Simbólico e a Violência Simbólica. 2015. Disponível em: <http://www.naomekahlo.com/single-post/2015/06/29/O-Poder-Simb\%C3\%B3lico-e-aViol\%C3\%AAncia-Simb\%C3\%B3lica> Acesso em 28 de maio de 2017.

COSTA, Nelson Nery. Ciência política. Rio de Janeiro: Forense, 2006.

DAGNINO, Evelina. Políticas culturais, democracia e projeto neoliberal. In: Rio de Janeiro, (15): 45-65, janeiro / abril de $2005 . \quad$ Disponível em:<http://www.forumrio.uerj.br/documentos/revista_15/15_dossie_EvelinaDagnino.pdf.>. Acesso em: 13 fev. 2016.

DALLARI, Dalmo de Abreu. Elementos de teoria geral do estado. 28. ed. São Paulo: Saraiva, 2009.

Declaração Universal dos Direitos Humanos. Disponível em: $<$ http://www.direitoshumanos.usp.br/index.php/Declara\%C3\%A7\%C3\%A3o-Universal-dos-

Direitos-Humanos/declaracao-universal-dos-direitos-humanos.html> Acesso em 30 de maio de 2017.

DIAS, Lúcia L. A política de segurança pública entre o monopólio legítimo da força e os direitos humanos: a experiência da Paraíba no pós 1988. Tese - Serviço Social. UFPE, 2010. Disponível em: <http://repositorio.ufpe.br:8080/bitstream/handle/123456789/9324/arquivo334_1.pdf?sequence=1 $>$. Acesso em 21 de maio de 2017.

DINIZ, Maria Helena. Compêndio de introdução à ciência do direito. São Paulo: Saraiva, 1988.

. Dicionário jurídico. 2. ed. São Paulo: Saraiva, 2005. v. 2.

. Norma constitucional e seus efeitos. São Paulo: Saraiva, 1997.

DURKHEIM, E. "O que é fato social?" In: As Regras do Método Sociológico. trad. Maria Isaura Pereira de Queiroz. 6a. ed. São Paulo: Companhia Editora Nacional, 1972.

GAGLIETTI, Mauro. O poder simbólico e a distancia entre os dois brasis: o formal e o informal. Revista Katálysis. v.9. n.1. jan/jun. Florianópolis - SC, 2006.

Página 188 Caderno de Ciências Sociais Aplicadas, Vitória da Conquista/BA, vol. 14, n² 24, ano 14, p. 171-190, jul/dez 2017. 
GARCIA, Maria. Desobediência civil - direito fundamental. São Paulo: Revista dos Tribunais, 2004.

INSTITUTO LATINO-AMERICANO DAS NAÇÕES UNIDAS PARA PREVENÇÃO DO DELITO E TRATAMENTO DO DELINQÜENTE (ILANUD). Quando o Estado agride a criança. Disponível em: <https://www.unicef.org/brazil/pt/Cap_06.pdf> Acesso em 18 de maio de 2017.

LOCKE, Jonh. Dois Tratados Sobre o Governo. São Paulo: Martins Fontes, 1998.

LOCKE, Jonh. Segundo Tratado sobre o governo civil: ensaio sobre a origem, os limites e os fins verdadeiros do governo civil. Petrópolis: RJ. 1994. p.132.

MACHADO, Kaline Pacífico de Brito. Normas Sociais e Normas Jurídicas: Uma abordagem Distintiva. Revista Olhares Plurais - Revista Eletrônica Multidisciplinar. vol. 1. no 12. 2015.

MARTINEZ, Solange D. T. Violência Institucional: Violação dos Direitos Humanos da Mulher. 2008. Disponível em: <http://www.recriaprudente.org.br/site/abre_artigo.asp?c=16> Acesso em 29 de maio de 2017.

MINISTÉRIO DA SAÚDE. Violência Intrafamiliar: Orientações para a prática em serviço. Cadernos de atenção básica $\mathrm{n}^{\mathrm{o}}$ 8. 2002. Disponível em <http://bvsms.saude.gov.br/bvs/publicacoes/cd05_19.pdf>. Acesso dia 30 de maio de 2017.

MONTEIRO, Maurício Gentil. O direito de resistência na ordem jurídica constitucional. Rio de Janeiro: Renovar, 2003.

MORTATI, C. 1969. Instituzionididirittopubblico, Cedam, Pádua 1969.

ONU - Organização das Nações Unidas. Declaração dos Direitos do Homem e do Cidadão, 1793.

RAWLS, John. Uma teoria da justiça. Tradução de VamirehChacon. Brasília: UnB, 1981.

REALE, Miguel.Experiência e Cultura. Campinas: Bookseller, 2000.

ROUSSEAU, Jean-Jacques. O Contrato Social e Outros Escritos. São Paulo: Cultrix, 1999.

ROUSSEAU. O Contrato Social. Coleção: Livros que mudaram o mundo. Tradução de Mário Franco de Sousa. Editorial Presença. 2010.

SAFFIOTI, Heleieth. Gênero patriarcado violência. 2ed. Sãopaulo: ExpressãoPopular: Fundação Perseu Abramo, 2015.

SÓFOCLES. Antígona. Brasília: Editora Universidade de Brasília, 1997.

Página 189 Caderno de Ciências Sociais Aplicadas, Vitória da Conquista/BA, vol. 14, nº 24, ano 14, p. 171-190, jul/dez 2017. 


\section{- CADERNOS de CIÉNCIAS SOCIAIS APLICADAS}

SOUZA, Jessé. A tolice da Inteligência Brasileira: ou como o país se deixa manipular pela elite.São Paulo: Le Ya, 2015.

SOUZA, M. de. A experiência da lei e a lei da experiência: ensaios sobre práticas sociais e subjetividades no Brasil. Rio de Janeiro: Revan. São Paulo: FAPESP, 1999.

TATAGIBA, Luciana. 1984, 1992 e 2013. Sobre ciclos de protestos e democracia do Brasil. Política e Sociedade. Florianópolis. Vol. 13, $\mathrm{n}^{\mathrm{o}}$ 28, Set./Dez. de 2014. Disponível em: $<$ https://periodicos.ufsc.br/index.php/politica/article/view/2175-7984.2014v13n28p35>. Acesso em: 7 abr. 2017.

VIEIRA, Regina Ferreira. Violência institucional e responsabilidade profissional na resposta ao abuso sexual de criança. 2013. Disponível em $<$ http://revistas.lis.ulusiada.pt/index.php/is/article/view/1199/1310 > Acesso em 20 de maio de 2017.

WARAT, L. A. Introdução geral ao Direito: a epistemologia jurídica da modernidade. Porto Alegre: Sérgio Fabris Editor, 1995.

WEBER, Max. Ciência e Política: Duas Vocações. $2^{a}$ ed. São Paulo: Editora Martin Claret Ltda. 2008. 